\title{
Activation of normal and inflamed fine articular afferent units by serotonin
}

\author{
M.K. Herbert* and R.F. Schmidt \\ Physiologisches Institut der Universität Würzburg, D-8700 Würzburg (Germany) \\ (Received 3 September 1991, revision received 27 January 1992, accepted 29 January 1992)
}

\begin{abstract}
Summary In cats anesthetized with alpha-chloralose, extracellular recordings were made from fine afferent units belonging to the medial articular nerve (MAN) of the knee joint. The excitatory and sensitizing effects on articular afferents of serotonin (5-HT) applied intra-arterially close to the joint were examined. The joints were either normal or an experimental arthritis had been induced some hours before the recording session. Bolus injections of $1.35-135 \mu \mathrm{g}$ 5-HT excited about $43 \%$ of group III (CV: $2.5-20 \mathrm{~m} / \mathrm{sec}$ ) and $73 \%$ of group IV units (CV: $<2.5 \mathrm{~m} / \mathrm{sec}$ ) from normal joints. The latency was usually between 10 and $30 \mathrm{sec}$, and the duration and size of the responses were dose-dependent. Fast group III units (CV: $>16 \mathrm{~m} / \mathrm{sec})$ and group II units (CV: $>20 \mathrm{~m} / \mathrm{sec}$ ) were never excited by 5-HT. Repetitive administration led to pronounced tachyphylaxis of the 5-HT response. Inflammation induced an enhanced sensitivity of group III articular afferent units to close intra-arterial application of 5-HT. In particular the total duration of each response was considerably prolonged (4-10 min against 1-2 min under normal conditions). At the same time the tachyphylaxis seen under normal conditions was greatly reduced. In contrast, group IV articular afferent units did not become sensitized to 5-HT in the course of inflammation. In normal joints 5-HT did not sensitize fine afferent units for movement-induced responses. However, after inflammation, a distinct sensitization to such movements by $5-\mathrm{HT}$ application could be observed both in group III and group IV fiber ranges. The sensitization had a short time course not exceeding $7 \mathrm{~min}$. The tonic component of the movement-induced response was more enhanced than the phasic one. The bolus application of 5-HT led to temporary vasoconstriction of the knee joint vessels. This vasoconstriction was especially pronounced in inflamed joints and impeded the access of subsequently applied substances to the terminal regions of the afferent units under observation.

It is concluded that the present results support the notion that 5-HT may participate in the mediation of pain from inflamed tissue such as an arthritic joint by exciting and sensitizing fine afferent units. During inflammation group III units are particularly sensitive to $5-\mathrm{HT}$ and, thus, may carry the bulk of the 5-HT-induced nociceptive messages.
\end{abstract}

Key words: Serotonin (5-HT); Articular afferent; Joint pain; Inflammation

\footnotetext{
* Present address: Dr. M.K. Herbert, Institut für Anaesthesiologie der Universität Würzburg, Josef-Schneider-Straße 2, D-8700 Würzburg, Germany.
}

Correspondence to: Prof. Dr. Robert F. Schmidt, Physiologisches Institut der Universität Würzburg, Röntgenring 9, D-8700 Würzburg, Germany. Tel.: (+49) 931-31730; Fax: (+49) 931-54553.

\section{Introduction}

Serotonin (5-HT) is usually considered to be one of the major mediators of inflammation (Spector and Willoughby 1964; Garcia Leme et al. 1973). In experi- 
ments studying the inflammatory processes of a carrageenan-induced inflammation, 5-HT (together with histamine) is considered to be especially involved in the early phase of inflammation (Spector and Willoughby 1964; Fekete and Kürti 1970; Crunkhorn et al. 1971; Di Rosa et al. 1971; Garcia Leme et al. 1973; Capasso et al. 1975). Under such circumstances 5-HT may well contribute to the hyperalgesia and pain of inflamed tissue. For instance, in experiments employing the blister base technique, 5-HT (among other 'algesic' agents) has been shown to be a potent stimulant for nociceptive endings (Armstrong et al. 1953; Keele and Armstrong 1964). It also evokes painful sensations in man when injected into the skin (Lindahl 1961), and pseud-affective responses in cats and dogs when injected intra-arterially (i.a.) into somatic, visceral, thoracic and cranial vessels (Guzman et al. 1962; Lim et al. 1962). In cats, high-threshold group IV afferent units from skeletal muscle are powerfully excited by $5-\mathrm{HT}$ injected into the blood stream (Mense and Schmidt 1974; Fock and Mense 1976).

At which tissue concentrations 5-HT exerts its potential effects as an inflammatory mediator and algesic agent is not known. So far, only serum concentrations of 5-HT have been determined. Both in healthy volunteers and in cats these concentrations have been found to be below those used in experimental i.a. applications (Erspamer 1953; Feldman et al. 1957; Costa and Rinaldi 1958; Zeitlin and Smith 1966; Hardeman et al. 1972; Artigas et al. 1985). Actually, there is no significant difference in the 5-HT serum content of healthy volunteers as against patients with joint diseases such as an active rheumatoid arthritis, and only a slightly higher 5-HT serum concentration in patients with a carcinoid syndrome (Robertson et al. 1962; Zeitlin and Smith 1966). These findings are presumably due to the fact that 5-HT circulating in the blood serum is quickly metabolized in the liver and the lung by monoaminooxidase (Garattini and Valzelli 1965) and also taken up into platelets (cf., Erspamer 1966). It seems likely, however, as discussed by Fock and Mense (1976), that such high concentrations of 5-HT as injected i.a. in our experiments occur locally in the interstitial extravascular space, e.g., as a consequence of platelet desintegration during blood clotting.

In the study reported here, the responsiveness of mechanosensitive fine articular afferent units to close arterial injection of 5-HT was determined. This study was based on background information of experiments recently performed in this laboratory to study changes in excitability which are induced in single afferents of articular nerves by various algesic and analgesic substances and, in particular, by an acute experimental arthritis (Kanaka et al. 1985; Schaible and Schmidt 1985; Heppelmann et al. 1986; Herbert and Schmidt 1986; Russel et al. 1987; Herbert et al. 1989).
In the present experiments we found that in normal joints a considerable proportion of those group III and group IV afferent units which were activated by joint movements also responded to low doses of 5-HT. An experimental inflammation sensitized group III units to 5-HT. This effect was much less pronounced in group IV units.

\section{Methods}

\section{General procedures}

The experiments were performed with cats of both sexes weighing $2.6-4.1 \mathrm{~kg}$. The animals were anesthetized by an intramuscular injection of $15 \mathrm{mg} / \mathrm{kg}$ ketamine hydrochloride (Ketanest) followed by i.v. injection of $40 \mathrm{mg} / \mathrm{kg}$ alpha-chloralose. Additional doses of chloralose $(10 \mathrm{mg} / \mathrm{kg}$, i.v.) were given as required to maintain a deep level of anesthesia throughout the experiments. All animals were immobilized with pancuronium bromide (Pancuronium Organon), 0.6 $\mathrm{mg} / \mathrm{h}$, i.v., and artificially ventilated. Blood pressure, end-expiratory $\mathrm{CO}_{2}$, and body temperature were monitored and kept at physiological levels.

\section{Preparation}

Dissection of the right leg, placement of the animal on the mounting table, performance of passive limb movements, as well as their registration, have been described in detail (Schaible and Schmidt 1985). In addition, for close i.a. application of test solutions, a fine cannula was inserted into the saphenous artery about $2 \mathrm{~cm}$ distal from the bifurcation of the femoral artery into the geniculate and saphenous arteries. Its tip pointed upstream and was usually about 1 $\mathrm{cm}$ distal from the point of origin of the geniculate from the saphenous arteries. Thus, any fluid injected upstream was washed down the geniculate artery by injection pressure and blood pressure After insertion, and repeatedly throughout the course of the experiments, a $1-\mathrm{ml}$ bolus injection of Tyrode solution containing $1 \%$ Evans blue was injected via this cannula in order to ascertain if the injection fluid had reached the joint tissue innervated by the MAN In some experiments irregular branches of the geniculate and saphenous arteries had to be tied off in order to minimize the loss of bolus fluid to the neighboring tissue.

\section{Recording, identification and data processing}

As in our previous studies, single units of the medial articular nerve (MAN) with conduction velocities (CVs) less than $2.5 \mathrm{~m} / \mathrm{sec}$ were classified as group IV fibers, those with $C V_{s}$ from 2.5 to 20 $\mathrm{m} / \mathrm{sec}$ as group III fibers, and those with CVs $>20 \mathrm{~m} / \mathrm{sec}$ as group II fibers. Since antidromically excited group IV postganglionic sympathetic efferent fibers could be mistaken for afferent ones, a group IV fiber was only assumed to be afferent if it was sensitive to local mechanical stimulation (probing) of the joint. Group III and IV units without detectable local mechanosensitivity were not included in the present sample. Such units may have receptive endings outside the joint region proper.

\section{Stimulation of joint afferent units}

With the knee joint in mid-position, the receptive field properties of an individual receptor were determined by jts responses to probing with a hand-held glass rod and a set of von Frey hairs. Thereafter the responses to passive limb movements were recorded in order to classify the unit as belonging to 1 of 4 distinct categories defined by Schaible and Schmidt (1983). It was examined whether a unit was strongly (A, category 1) or weakly activated (WA, category 2) by movements within the working range of the joint (extension and 
flexion starting from semiflexed position, supination and pronation starting from various angles between extension and flexion) or whether it was only activated by noxious movements (NX, category 3 , supination and pronation against the resistance of the joint tissue) or not even activated by innocuous and noxious movements (NA, category 4). To avoid sensitizing or desensitizing effects of subsequent noxious movements, such stimuli were applied in intervals of at least $3 \mathrm{~min}$. In our experience no sensitizing or desensitizing effect occurred using this testing procedure. If there was resting activity in the absence of intentional stimulation, it was recorded to determine its baseline level.

For cnemical stimulation of the fine articular units, synthetic serotonin (5-HT creatinine sulphate) was dissolved in Tyrode solution at room temperature. The doses indicated refer to 5-HT as free base. Each injection was done in the following way: $0.3 \mathrm{ml}$ of $5-\mathrm{HT}$ solution was filled into the arterial catheter. Thereafter it was injected with $1 \mathrm{ml}$ of Tyrode solution. The injection was completed in about $3 \mathrm{sec}$. Further injection of another $1 \mathrm{ml}$ of Tyrode solution was given in order to clean the tube system from remaining traces of 5-HT. This mode of application is identical to that described in (Franz and Mense 1975; Fock and Mense 1976) for chemical stimulation of fine muscle afferents. Therefore, the results obtained with fine muscle afferents can be readily compared with those obtained here (see Discussion).

Prior to any application of 5-HT, an injection of $0.3 \mathrm{ml}$ of a twice isotonic $(320 \mathrm{mmol} / \mathrm{l})$ solution of potassium chloride was used (again with $1 \mathrm{ml}$ of Tyrode) to test the accessibility of the units via the blood vessels. Such an injection typically evokes a rapid burst of impulses at short latency in fine articular afferent units (see Results for details). If this short latency discharge was absent, no test with 5-HT was carried out.

Testing the effects of 5-HT on a second afferent unit was performed at least 2 , usually more than 3 , hours later to insure that the 2nd fiber studied was no longer under the influence of 5-HT injected when studying the preceding unit.

In most cases in which $\mathrm{KCl}$ evoked a clear-cut burst of impulses, a receptive field could be identified. Vice versa, only in rare cases could a receptive field be found, despite a lack of response to $\mathrm{KCl}$. Quite a number of units in group III and group IV fiber ranges reponded to $\mathrm{KCl}$ with 1-3 impulses only. In such cases we could never find a receptive field, and these units were excluded. We suspect that group IV units were postganglionic sympathetic fibers the axons of which were depolarized by $\mathrm{KCl}$ to give a few antidromic impulses. The group III units probably passed through the MAN to surrounding tissue.

\section{Experimental arthritis}

Acute inflammation of the knee joint was evoked in 18 cats in the beginning of the experiment by injecting $0.4 \mathrm{ml}$ of a $4 \%$ solution of kaolin plus $0.3 \mathrm{ml}$ of a $2 \%$ solution of carrageenan into the knee joint cavity. The knee was regularly flexed and extended for $15 \mathrm{~min}$ immediately after injection of each compound. Each of these substances injected individually can induce an acute inflammation, but the combined use of these 2 agents appears to cause a greater degree of inflammation that follows a more consistent time course than does either agent alone (Schaible and Schmidt 1985).

\section{Results}

\section{Responses of fine articular afferents to $\mathrm{KCl}$}

Prior to 5-HT application, the mechanosensibility of each unit was tested as described in Methods. Eventual resting discharges were registered for $10 \mathrm{~min}$ after a pause of 10 min without any manipulation on the joint.

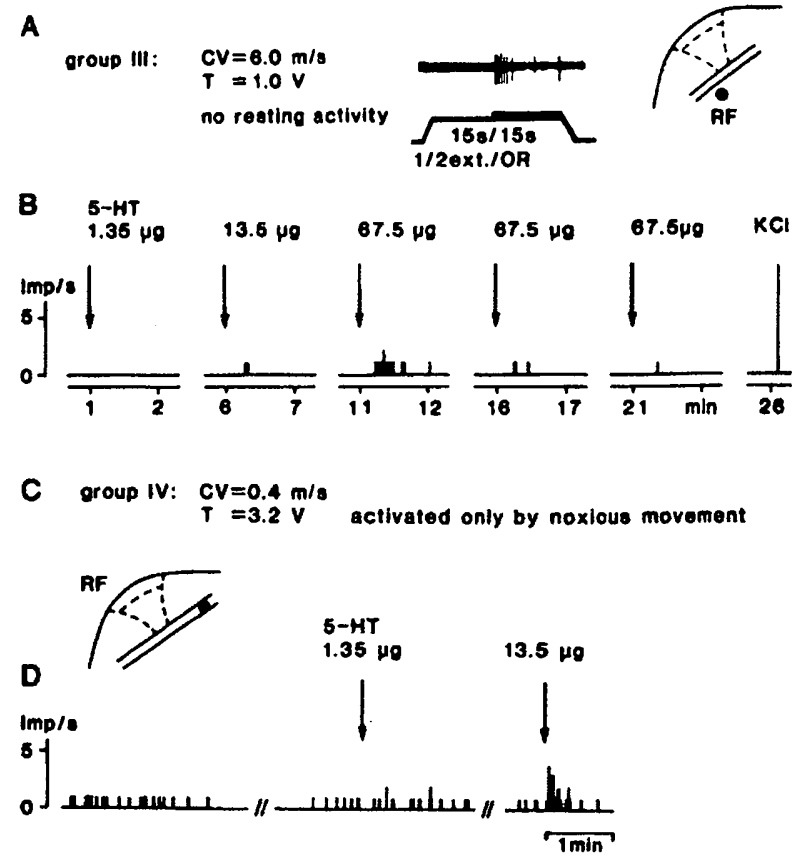

Fig. 1. Responses to 5-HT of group III (A, B) and group VI (C, D) units from normal joints. A: group III afferent unit with a conduction velocity $(\mathrm{CV})$ of $6.0 \mathrm{~m} / \mathrm{sec}$ and an electrical threshold $(\mathrm{T})$ of $1.0 \mathrm{~V}$ (square pulse of $0.5 \mathrm{msec}$ duration applied to the MAN) had no resting activity, a low threshold, and responded weakly to outward rotation in half extension ( $1 / 2$ ext./OR). The dot (RF) in the schematic drawing indicates the receptive field of the unit on the medial region of the knee joint. B: injection of $13.5 \mu \mathrm{g}$ of $5-\mathrm{HT}$ evoked a brief response with a latency of $15 \mathrm{sec}$ after the end of injection. A larger dose of 5-HT $(67.5 \mu \mathrm{g})$ elicited a stronger response with pronounced tachyphylaxis to the 2 nd and 3 rd injection of the same dose $(67.5 \mu \mathrm{g})$ in 5 -min intervals. Although being tachyphylactic to 5-HT, the unit was fully excitable by $\mathrm{KCl}$. The time window (address advance time) used integrates impulses for $1 \mathrm{sec}$ (shown in this and the following figures.) C: group IV unit with a CV of 0.4 $\mathrm{m} / \mathrm{sec}$ was activated only by noxious movements. The receptive field (RF, dot) was located on the collateral ligament. D: the unit had low resting activity, and was insensitive to $1.35 \mu \mathrm{g}$ but was excited by 13.5 $\mu \mathrm{g}$ of 5-HT. The latency was very short, and activity arose immediately after finishing bolus injection.

Thereafter Tyrode solution was injected i.a. in order to eliminate unspecific effects due to the injection itself.

These preliminaries completed an injection of $0.3 \mathrm{ml}$ of potassium chloride in a concentration of $320 \mathrm{mmol} / \mathrm{l}$, which in most cases elicited a short burst of impulses at short latency. Examples of such discharges are shown in Figs. 1B and 9. As mentioned in Methods, units without a definite response to $\mathrm{KCl}$ application were not investigated any further (for details on the characteristics of $\mathrm{KCl}$ evoked discharges see Kanaka et al. 1985).

\section{Responses to 5-HT of units from normal joints}

The responses of various mechanosensitive articular fine afferent units from normal joints to close i.a. application to 5-HT are documented in Figs. 1-3. The 

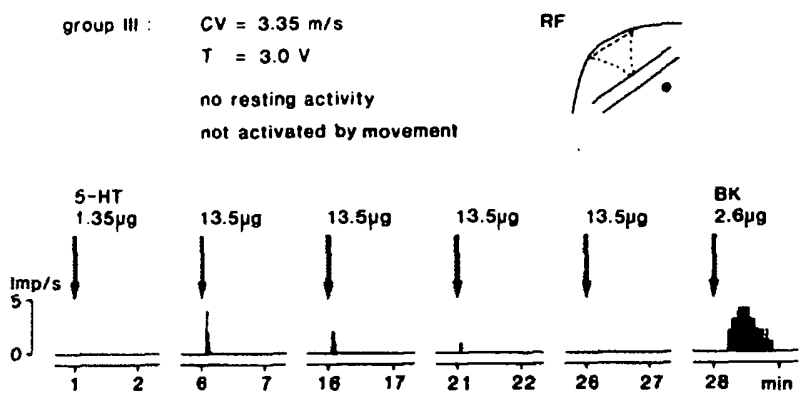

Fig. 2. Response to 5-HT injected i.a. of a high-threshold afferent group III unit from normal joint. The unit with a CV of $3.35 \mathrm{~m} / \mathrm{sec}$ was not activated by any joint movement and had no resting activity. The threshold dose of 5-HT to elicit an excitation was $13.5 \mu \mathrm{g}$, and the responses to subsequent injections of the same dose of 5-HT showed clear tachyphylaxis. The unit was even unexcitable to 5-HT after the 4th injection of $13.5 \mu \mathrm{g}$, but still sensitive to $2.6 \mu \mathrm{g}$ of BK 2 min later. The activity to 5-HT occurred within $3 \mathrm{sec}$ after the end of

the i.a. injection, whereas the latency to $B K$ was about $12 \mathrm{sec}$

specimen records of Fig. 1A, B are from a group III unit with a CV of $6.0 \mathrm{~m} / \mathrm{sec}$. The unit had no resting activity, and it had a low threshold to outward rotation of the joint. Injection of $1.35 \mu \mathrm{g}$ of 5-HT (at the left in Fig. 1B) did not evoke any activity. Increasing the dose of 5 -HT to $13.5 \mu \mathrm{g}$ evoked a brief burst of 2 impulses with a latency of $15 \mathrm{sec}$ after the end of the injection. A further increase of the dose of 5-HT to $67.5 \mu \mathrm{g}$ elicited 17 impulses with a latency of only $12 \mathrm{sec}$.

Comparable results with a group IV unit are shown in Fig. $1 C$ and D and with another group III unit in Fig. 2. The group IV unit (Fig. 1C, D) had a low resting activity, a CV of $0.4 \mathrm{~m} / \mathrm{sec}$, and it could only be activated by noxious joint movements. The threshold dose for an activation by $5-\mathrm{HT}$ was $13.5 \mu \mathrm{g}$. The group III unit in Fig. 2 had no resting activity and was not activated by any joint movement (unit of category 4).

Usually in normal joints the 5-HT evoked discharges had a uniform time course with a clear-cut beginning and end of activity, the highest frequencies occurring early in the discharge, and its total duration being in the order of $60-90 \mathrm{sec}$. The threshold dose necessary to excite both group III and group IV units varied between 1.35 and $135 \mu \mathrm{g}$ (Fig. 3). No excitation was seen with a dose of $0.135 \mu \mathrm{g}$. In most cases the threshold dose was $13.5 \mu \mathrm{g}$ (Fig. 3). As a rule doses above threshold led to an increase in the evoked responses (cf., Fig. 1).

The latency of the 5-HT evoked responses was usually between 10 and $30 \mathrm{sec}$ from the end of the bolus injection of about $1-3 \mathrm{sec}$ duration (Fig. 7, hatched columns). Most latencies were between 13 and $20 \mathrm{sec}$. Only 4 units ( 1 group III and 3 group IV) responded immediately after the end of the injection, i.e., with latencies of $3 \mathrm{sec}$ or even less (Fig. 7). Two of these 4 units were recorded in the same experiment. None of the 4 units showed any special characteristics which could have been related to the short response latencies upon 5-HT injection.

Units with background activity (frequency usually well below $1 / \mathrm{sec}$, Fig. 1D), both in group III and group IV fiber ranges, showed no difference to silent units in their excitability to 5-HT. They had the same threshold doses for excitation, and the time course of the evoked responses was also similar in both types of units.

No relation was found between the CVs of group III and group IV units and their threshold or response behavior to 5-HT. Group III units with CVs above 16 $\mathrm{m} / \mathrm{sec}$ (4 units), and articular group II units in the MAN were practically never excited by bolus injections of 5-HT in amounts up to $135 \mu \mathrm{g}$, although they all responded readily to i.a. administration of potassium chloride. Of 5 group II units systematically tested, only 1 with a conduction velocity of $20 \mathrm{~m} / \mathrm{sec}$ responded to $135 \mu \mathrm{g}$ of 5-HT with an unusually long latency of 65 sec and with an equally uncommon long response duration of $9 \mathrm{~min}$.

The response behavior to repetitive injections of 5-HT is illustrated in the specimen records of Figs. 1 and 2. In these units, as in others similarly tested, the discharge rates decreased gradually during successive injections. Usually the tachyphlylaxis was very pronounced regardless whether low or high doses of 5-HT were administered. For instance, in Fig. 2, the 4th injection of $13.5 \mu \mathrm{g}$ of 5 -HT did not evoke a response anymore. Nevertheless the unit was still very sensitive to injection of a small amount $(2.6 \mu \mathrm{g})$ of bradykinin (BK) (Fig. 2).

Recovery to control responses was usually slow, taking at least $15-20 \mathrm{~min}$, and often $30 \mathrm{~min}$ or more. The rate of recovery neither seemed to be correlated to the CV of the unit nor to the amount of 5-HT given. (The use of repeated applications of higher doses of 5-HT was limited by the occurrence of a decrease in
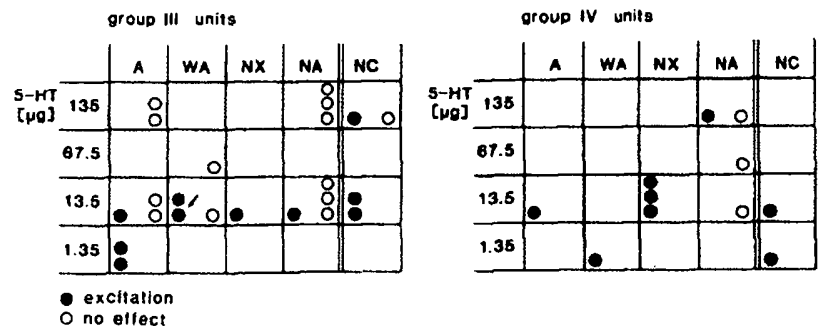

Fig. 3. Excitability of group III and group IV units from 4 normal joints and threshold doses of 5-HT in relationship to the responses to joint movement. The units were classified into the categories: (A) activated by non-noxious movement, (WA) weakly activated by nonnoxious movement, (NX) activated only by noxious movement and (NA) not activated by any movement. A few units were not classified (NC) according to their response to movement. Black dots represent those units sensitive to 5-HT with threshold doses of 5-HT indicated on the left. Open circles denote the units not excitable by the highest dose of 5-HT tested as indicated on the left. The arrow in the left diagram points to the unit displayed in Fig. IA,B. 
blood pressure to each injection of 5-HT in doses of $13.5 \mu \mathrm{g}$ and, in particular, $135 \mu \mathrm{g}$.) In 1 group IV unit with a resting activity of about $40 \mathrm{imp} / \mathrm{min}$ (and weakly activated by non-noxious movements) a pronounced excitation to $135 \mu \mathrm{g}$ of 5-HT was followed by a longlasting depression of the resting activity.

Fig. 3 displays the relation between the excitability of fine articular afferents from normal joints to 5-HT and their threshold to joint movements as classified by Schaible and Schmidt (1983). In the group III fiber range about $50 \%$ of the units excitable by non-noxious (A, WA) or noxious movements (NX) were excited by 5-HT, the usual threshold dose being $13.5 \mu \mathrm{g}$. Of those 7 units which could not be activated by any movement (NA, Fig. 3) 6 were also insensitive to 5-HT. All 7 units had no resting activity; doses up to $135 \mu \mathrm{g}$ were tested in 3 units.

In the group IV fiber range, all units sensitive to movement (A, WA, NX) also responded to 5-HT. Again the most frequent threshold dose was $13.5 \mu \mathrm{g}$. Of the 4 units not activated by any movement (NA), only 1 responded to 5-HT (cf., comparable to results with group III units of this type). In this unit a dose of $135 \mu \mathrm{g}$ of 5-HT was required to evoke a response.

\section{Responses to 5-HT of units from inflamed joints}

An acute experimental arthritis, induced as described in Methods, leads to marked changes in the receptive properties of non-nociceptive, nociceptive and mechanically inexcitable fine articular afferents (Schaible and Schmidt 1985, 1988b): all of them are considerably sensitized to movement. As a consequence, part of the low-threshold afferents and most of the highthreshold ones show enhanced responsiveness to movement, and those units which are unresponsive to mechanical stimuli in the normal joint now respond to movement in the normal working range of the joint. As a second major consequence of such an arthritis, spontaneous discharges appear in previously silent units, and an enhancement of activity is seen in those units spontaneously active in the normal joint.

In the present experiments it is shown that inflammation not only leads to a considerable sensitization of group III articular afferents to movements but also to 5-HT. Specimen records illustrating the response behavior to 5-HT under these conditions are shown in Figs. 4 and 5. Silent units (Fig. 4A) as well as those with resting activity (Figs. 4B and 5) respond to 5-HT, often to the low concentration of $1.35 \mu \mathrm{g}$ (Fig. 4A). Particularly remarkable is the duration of the responses in Figs. 4B and 5. Four to 10 min elapse before the discharges return to the control (resting) value (against average response durations of 1-2 min under normal conditions). Such long response durations were seen in another 3 group III and 1 group IV units from inflamed joints. In the other units excited by $5-\mathrm{HT}$ the
A group III

$C V=14.8 \mathrm{~m} / \mathrm{s} \quad T=0.18 \mathrm{~V}$ Zetivated by nonnoxloue movement

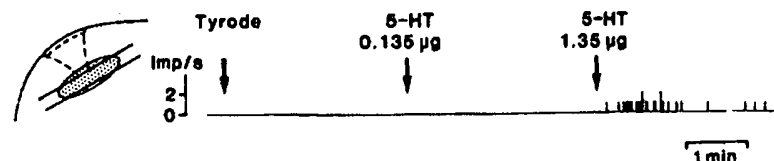

B group III :

$C V=3.6 \mathrm{~m} / \mathrm{s} \quad T=1.1 \mathrm{~V} \quad$ not classtfled

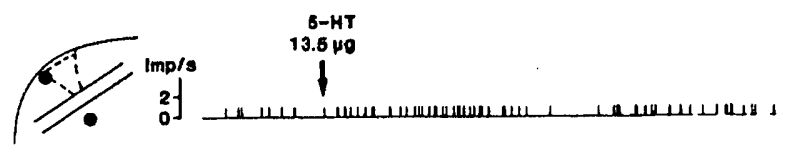

Imp/s

Fig. 4. Responses to 5-HT of group III (A) units from inflamed joints. A: group III unit with a CV of $14.8 \mathrm{~m} / \mathrm{sec}$ was activated by non-noxious movement and had a large receptive field (stippled area). The unit was neither excited by Tyrode nor $0.135 \mu \mathrm{g}$ of 5-HT, but the low dose of $1.35 \mu \mathrm{g}$ evoked comparatively long activity. B group III unit with a $\mathrm{CV}$ of $3.6 \mathrm{~m} / \mathrm{sec}$ and ongoing resting activity had 2 distinct receptive fields (dots). Excitation occurred after injection of $13.5 \mu \mathrm{g}$ of $5-\mathrm{HT}$ and more than $10 \mathrm{~min}$ elapsed before the discharges returned to the resting value after $135 \mu \mathrm{g}$ of 5-HT.

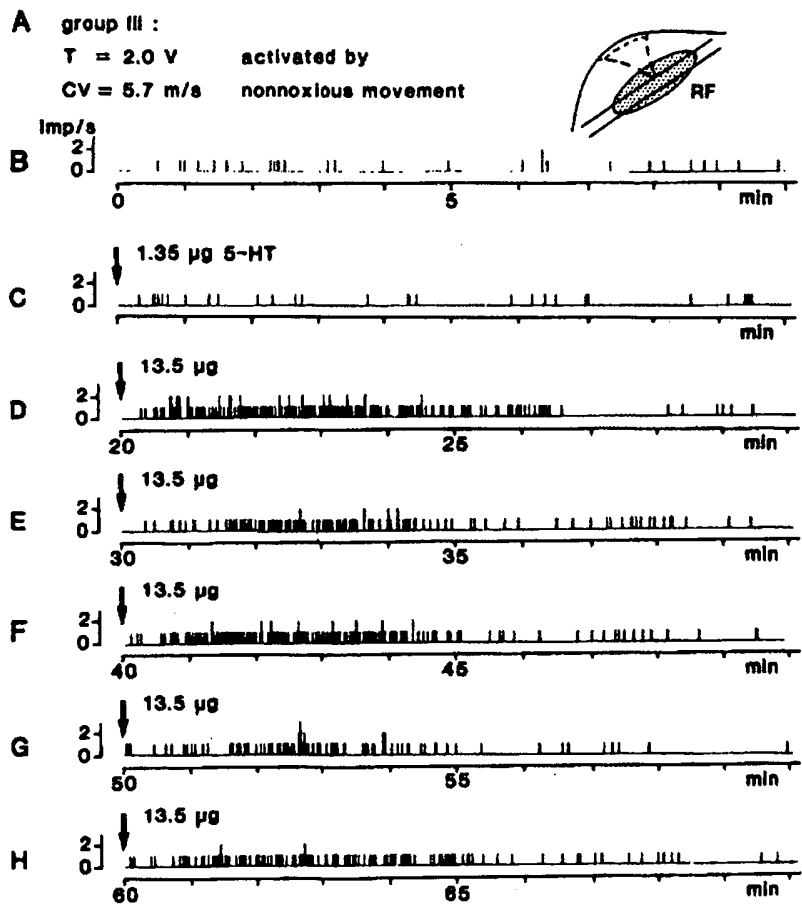

Fig. 5. Long-lasting response and little tachyphylaxis to repeated injections of 5-HT of a group III unit from inflamed joint. A: group III unit conducting with $5.7 \mathrm{~m} / \mathrm{sec}(\mathrm{CV})$ had a large receptive field (stippled area) on the medial collateral ligament and was activated by non-noxious movement. B: resting activity of $2.8 \pm 2.0 \mathrm{imp} / \mathrm{min}$ (mean \pm S.D.) was not affected by $1.35 \mu \mathrm{g}$ of 5-HT (C). D: injection of $13.5 \mu \mathrm{g}$ evoked a long-lasting excitation (about $6 \mathrm{~min}$ ) with only little tachyphylaxis (E-H) to repeated injections of $13.5 \mu \mathrm{g}$ of 5-HT. 


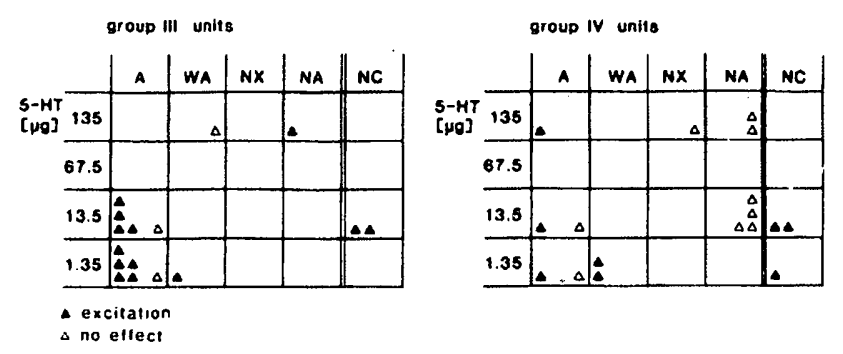

Fig. 6. Excitability of group III and group IV units from inflamed joints and threshold doses of 5-HT in relationship to the responses to joint movement. The units were classified into the categories: (A) activated by non-noxious movement, (WA) weakly activated by nonnoxious movement, (NX) activated only by noxious movement, and (NA) not activated by any movement. A few units were not classified (NC) according their responses to movement. Black triangles represent those units sensitive to 5-HT, with threshold doses of 5-HT indicated on the left. Open triangles denote the units not excitable by the highest dose of 5-HT tested as indicated on the left. Most of group III units were activated by non-noxious movement and 6 of 10 units were excited by the low dose of $13.5 \mu \mathrm{g}$ of 5 - HT. Contrary to group III units, group IV units do not appear to become sensitized to 5-HT by acute arthritis.

response duration was similar to that in afferents from non-inflamed joints.

Units with long response durations to 5-HT had another remarkable feature which is illustrated in Fig. 5D-H; they showed only little tachyphylaxis to repeated injections of 5-HT. All 6 units showing this response behavior were active at rest. Their threshold doses of activation were either 1.35 or $13.5 \mu \mathrm{g}$ of $5-\mathrm{HT}$. Four of them had low threshold to movements (class A units in Fig. 6); 2 were not classified.

Contrary to group III units, group IV units did not seem to become sensitized to 5-HT in the course of inflammation. This difference is clearly seen in Fig. 6 where the relation between the excitability of fine articular units from inflamed joints and their threshold to movement is shown. In the sample of 16 group III units, 13 responded to $5-\mathrm{HT}(81 \%)$, most of them having low thresholds to movement (class $\mathrm{A}$ in Fig. 6, left-hand diagram). In contrast, in the sample of 17 group IV units (right-hand diagram), only 8 were excited by 5 -HT application.

The latency of the 5-HT evoked responses was in the same time order as in the units from normal joints (Fig. 7, stippled columns). Just as in normal joints, a few units responded immediately at the end of the injection. Four units showed responses with rather long latencies (31-40 sec in Fig. 7). Such long latencies were not seen when recording units from normal joints.

\section{Sensitization by 5-HT for mechanically evoked responses}

In units from normal joints no (or only weak) sensitization by 5-HT for mechanically evoked responses could be observed in both group III and group IV fiber ranges. In a sample of 11 units ( 7 group III, 4 group
Latency to 5-HT Injection

of Group III and IV Units

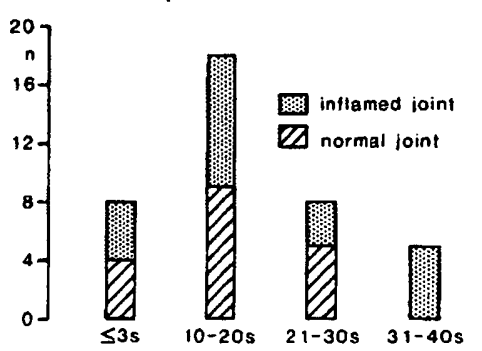

Fig. 7. Latencies of the 5-HT evoked responses in normal and inflamed joints. In most units the activity occurred after 10-20 sec. Four units from both normal and inflamed joints responded immediately at the end of the injection of 5-HT (latency $<3 \mathrm{sec}$ ). Four units from inflamed joints showed responses with rather long latencies $(31-40 \mathrm{sec})$.

IV), only 1 unit, responding to noxious outward rotation in half flexion prior to the application of $135 \mu \mathrm{g}$ of 5-HT, afterwards responded weakly to non-noxious outward rotation. The other 10 units showed no change in their response behavior following 5-HT application, regardless of whether they could/could not be activated by mechanical stimuli.

In units from inflamed joints a more distinct sensitization by 5 -HT to mechanically evoked responses was seen in 4 of 9 units tested ( 4 group III, 5 group IV). An example of the test procedure and its results is illus-
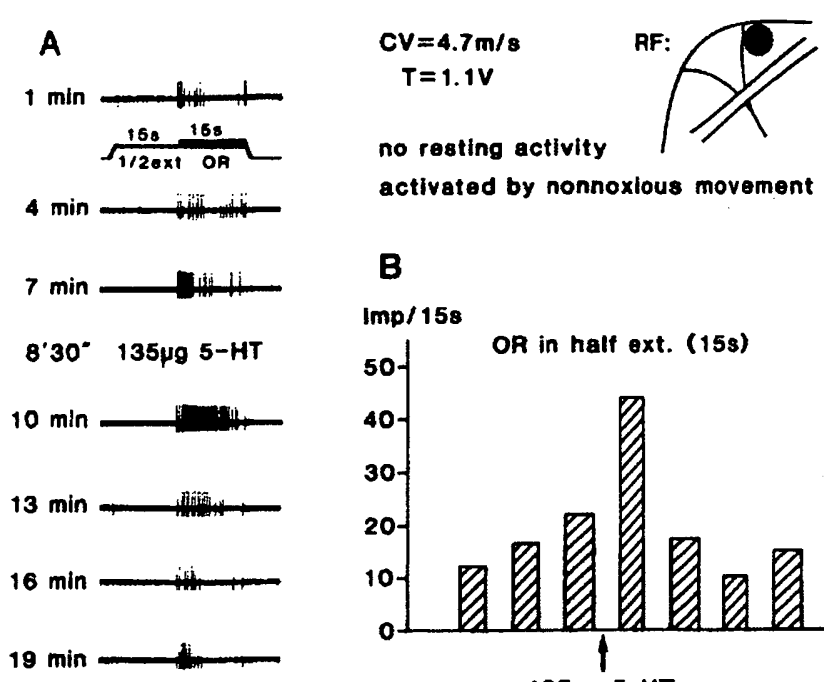

activated by nonnoxious movement

\section{B}

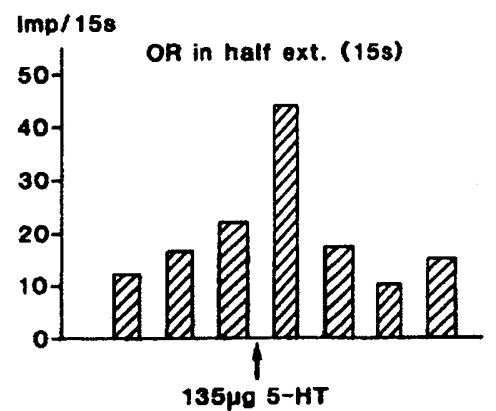

Fig. 8. Sensitization by 5-HT for mechanically evoked responses. The group III unit (CV: $4.7 \mathrm{~m} / \mathrm{sec}$ ) has been recorded from an inflamed joint and displayed no resting activity. The unit had low threshold to joint movement and responded weakly to outward rotation in the half extended knee joint ( $1 / 2 \mathrm{ext} / \mathrm{OR}-15 \mathrm{sec} / 15 \mathrm{sec})$. (A,B) The number of impulses evoked by outward rotation (15 sec) doubled within $3 \mathrm{~min}$ after injection of $135 \mu \mathrm{g}$ of $5-\mathrm{HT}$. The tonic component of movement-evoked discharges was more enhanced than the phasic one. The sensitization had only a short duration and was back to the control level in less than $5 \mathrm{~min}$. 
trated in Fig. 8. Here, the number of impulses evoked by an outward rotation doubled within $3 \mathrm{~min}$ after the 5-HT application. Three minutes later the mechanically evoked responses were back to the control level. A similarly short time course of the sensitization (not exceeding $7 \mathrm{~min}$ ) was observed in the other 3 units. The sensitization enhanced the tonic component of mechanically evoked discharges more than the phasic one (cf., Fig. 8).

\section{Local vasoconstriction by 5-HT modifying afferent dis- charges}

Close i.a. injection of 5-HT, particularly in doses of $13.5 \mu \mathrm{g}$ or more, causes vasoconstriction of the knee joint vessels which can easily be visualized by subsequent i.a. injections of Evans blue. This vasoconstriction is especially pronounced in inflamed joints. The vasoconstriction presumably impedes (reduces/obstructs) the access of the substances applied i.a. to the terminals of the fine afferent units, and their responses to such injections will be reduced in comparison to control injections. An example is given in Fig. 9A. This group III unit from inflamed knee joint responded with the usual burst of impulses to the standard bolus injection of $\mathrm{KCl}$. However, after an application of 135 $\mu \mathrm{g}$ of $5-\mathrm{HT}$ the subsequent $\mathrm{KCl}$ injections did not lead to any responses for some time after injection, and it took $30 \mathrm{~min}$ before the responses to $\mathrm{KCl}$ were fully recovered. This sequence was fully repeatable in this unit, and it was also seen in 4 other units from inflamed joints tested in the same way.

Two further reflections of the local vasoconstriction induced by $5-\mathrm{HT}$ in the knee joint vessels are illustrated in Fig. 9B-D. Fig. 9B shows the discharges in a fast afferent unit (presumably a pacinian corpuscle) from knee joint capsule which were induced by the pulse waves, and thus absolutely synchronous with the heart beat. Injection of 5-HT in the small dose of 1.35 $\mu \mathrm{g}$ led to asynchronous responses, indicating that the pulse wave was locally reduced in amplitude. Higher doses of 5-HT led to more pronouced uncoupling (Fig. 9C) which was dose dependant and fully reversible.

A
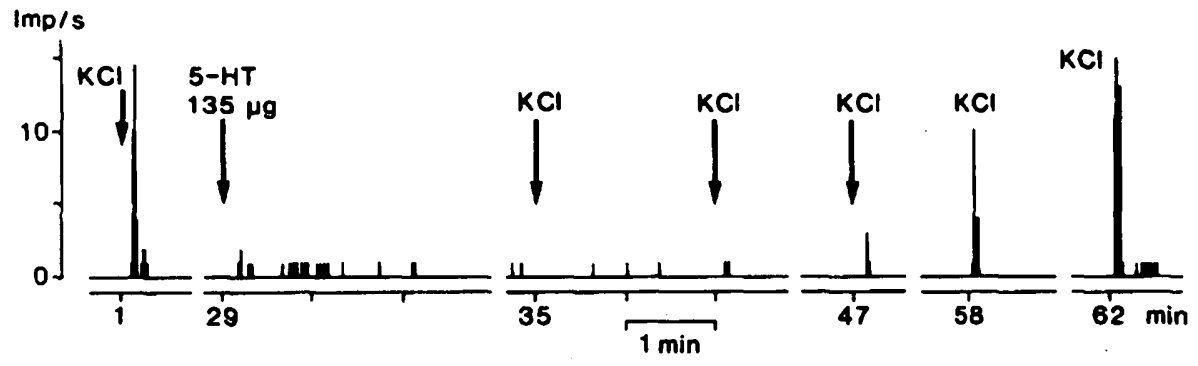

B

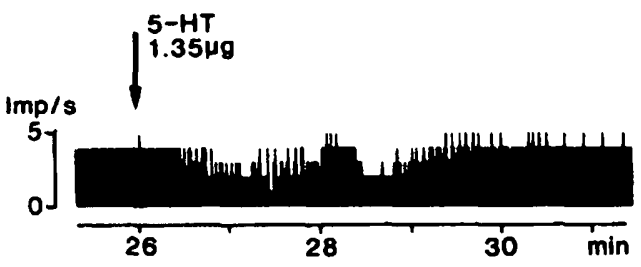

C

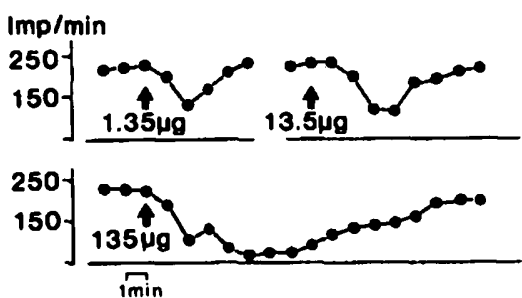

D

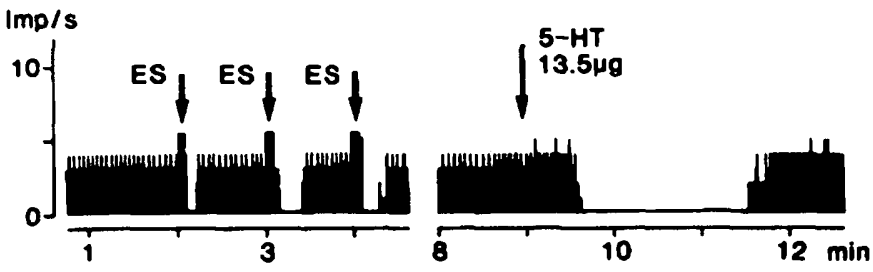

Fig. 9. Local vasoconstriction by 5-HT in cat knee joint modifying afferent discharges. A: group III unit from inflamed knee joint responded to $\mathrm{KCl}$ with the usual burst of impulses. After an application of $135 \mu \mathrm{g}$ of $5-\mathrm{HT}$, there was no response to subsequent injections of $\mathrm{KCl}$, and it took up to $30 \mathrm{~min}$ until the responses to $\mathrm{KCl}$ were fully recovered. B-D: effect of 5-HT on the discharges of a fast afferent unit (presumably a pacinian corpuscle) from knee joint capsule. The discharges were induced by the pulse waves and absolutely synchronous to heart beat of the cat. The small dose of $1.35 \mu \mathrm{g}$ of 5-HT led to asynchronous responses, indicating a reduced amplitude of the pulse wave. C: in the same unit, the uncoupling was dose dependent and always fully reversible. D: uncoupling of the heart beat synchronous discharges of a pacinian corpuscle can also be activated by electrical stimulation (ES) of the MAN sufficient ( $10 \mathrm{~V}$, square pulse of $0.5 \mathrm{msec}$ ) to excite postganglionic sympathetic fibers with vasoconstrictor function. The vasoconstrictor effect to ES was reproducible in this and other (not shown) units. Application of $13.5 \mu \mathrm{g}$ of 5-HT induced an uncoupling after a latency of $30 \mathrm{sec}$ with a much slower recovery as compared to that after electrical nerve stimulation. 
Finally, Fig. 9D illustrates that this uncoupling of the synchronous responses of a fast afferent unit from the heart beat can also be achieved by electrically stimulating the MAN at a strength sufficient to excite the postganglionic sympathetic fibers with vasoconstrictor function. In the example shown a complete inhibition of the afferent discharges was achieved. Such a complete inhibition was also obtained with a close i.a. injection of $13.5 \mu \mathrm{g}$ of 5-HT. As seen in Fig. 9D recovery was much slower following 5-HT application as compared to nerve stimulation.

\section{Discussion}

The major finding of this investigation is that a considerable proportion of group III (43\%) and group IV articular afferent fibers (73\%) in the MAN with mechanosensitive receptive fields on medial and anteromedial regions of the normal knee joint can be excited by $5-\mathrm{HT}$ administered in small doses by close i.a. injection and that acute experimental arthritis enhances the sensitivity of group III but not of group IV units to 5-HT. These results are supplemented by the findings that in normal joints 5-HT applied in this way did not sensitize fine afferent units for movement-induced responses whereas, after inflammation, a distinct sensitization to such movements could be seen.

In normal joints, the excitability to 5-HT is preferentially restricted to those articular units which are sensitive to innocuous or noxious joint movements whereas those which remained silent to any movement were also insensitive to even high doses of 5-HT. No relation was seen to the presence or absence of spontaneous activity in any of these units. This is a remarkable observation in view of the fact that with histamine the same units can only be excited if spontaneous activity is present (in normal as well as in inflamed joints: Herbert and Schmidt 1986).

Group II units (CVs $>20 \mathrm{~m} / \mathrm{sec}$ ) as well as group III units with CVs greater than $16 \mathrm{~m} / \mathrm{sec}$ were never excited by 5-HT, although both types of units were readily excited by injection of potassium ions, just as the other fine afferent units were. In regard to group II units, these findings are well in line with those obtained when testing other aspects of the chemosensitivity of group Il afferents, such as their (in)sensitivity to BK (Kanaka et al. 1985), to histamine (Herbert and Schmidt 1986), to various prostaglandins (Heppelmann et al. 1985; Schaible and Schmidt 1988a; Schepelmann et al. 1990) or to capsaicin (He et al. 1988).

On the other hand, in the experiments just quoted, the fast group III units did not show a difference in chemosensitivity, except to capsaicin, compared to the slow ones. Here, as with 5-HT, the fast group III units (CVs $>11.3 \mathrm{~m} / \mathrm{sec}$ ) were completely insensitive to close i.a. application of capsaicin whereas $43 \%$ of those in the conduction range of $2.5-11.3 \mathrm{~m} / \mathrm{sec}$ were excited. While it is tempting to see some functional relationship between these 2 observations, e.g., by speculating that both substances exert their action at some kind of receptor which only slow fine afferents possess, any such comparison should not be carried too far because other response characteristics differ widely, in particular the latencies (which are extremely short for capsaicin) and the tachyphylaxis following repeated injections (which is absent with capsaicin).

Response latencies to 5-HT application and the tachyphylaxis observed following repeated applications of suprathreshold doses are similar to those seen upon BK administration (Kanaka et al 1985). Again, however, the differences in the response pattern are at least just as frequent. First, practically all fine articular afferents respond to BK but by far not all of them are excited by 5-HT. Second, the average threshold dose is about one order of magnitude lower for BK than for 5-HT. Third, in normal joints, the average burst of impulses evoked by a suprathreshold administration of 5-HT is shorter and less intense than that seen after BK (inflammation enhances and prolongs group III but not group IV responses to 5-HT; no comparable observations are available for $\mathrm{BK}$ ). The delay of the 5-HT evoked responses might be due to the release and action of mediators from 5-HT-sensitive cells such as platelets, mast cells or lymphocytes. However, a 5-HT action on specific receptors seems more likely because it is a common feature of afferent units in this (Kanaka et al. 1985; Herbert and Schmidt 1986) and other preparations (muscle afferents: Fock and Mense 1976; rat articular afferents: Birell et al. 1990) to respond to close arterial injection of inflammatory mediators with a delay of several seconds.

No cross-tachyphylaxis could be observed between 5-HT and BK, a finding which together with the other ones mentioned in this paragraph points to different receptor sites for BK and 5-HT at fine afferent terminals. A similar conclusion was drawn when, in fine muscle afferents, the excitatory effects of 5-HT were compared with those of BK (Fock and Mense 1976). Here again, 5-HT was far less potent than BK (about $1: 30$ on a molar ratio), the threshold injection dose for 5-HT was in the same order of magnitude as reported here $(13.5 \mu \mathrm{g})$, and $44 \%$ of the units responded, and the time course of the evoked burst of impulses was clearly different from that evoked by BK.

In the skin of the cat, 5-HT (as well as BK) excites afferent units of all fiber classes, thick myelinated (group II) as well as thin myelinated (group III) and unmyelinated (group IV) fibers (Beck and Handwerker 1974). However, when the afferent fibers were classified according to their receptor characteristics, it was seen that among the group IV units all receptor classes 
were activated by $5-\mathrm{HT}$ and BK; however, among the myelinated fibers, only definite groups of receptors proved to be responsive, i.e., the slowly adapting lowand high-threshold mechanoreceptors with group III afferents and the slowly adapting mechanoreceptors supplied by group $\amalg$ fibers. Again, there was a pronounced tachyphylaxis upon repeated injections of the same agent without any cross-tachyphylaxis between them (this finding is in agreement with the independent tachyphylaxis of the pain-producing effect of both substances in blister base experiments: Keele and Armstrong 1964).

The effects of 5-HT on articular sensory receptors have also been investigated in a different species, the rat (Birrell et al. 1990), but with another model to induce arthritis (rat adjuvant-induced polyarthritis) and a quite different mode of classifying joint receptors. Adjuvant-induced polyarthritis serves as a model for chronic inflammatory pain (see Colpaert 1987). Unidentified chemosensitive afferents and highthreshold mechanoreceptors from rat medial plantar nerve were excited in a fast transient burst, followed by a delayed slow longer-lasting excitation (Birrell et al. 1990). These 2 seperate components of 5-HT-induced excitation were only observed in rat knee joint afferents. The increase of mechanosensivity to local pressure in rat joint afferents due to 5-HT seems to be more pronounced than the sensitization to mechanically evoked responses during joint movement in cat. The doses of 5-HT injected i.a. in the rat (Birrell et al. 1990) were similar to those in our experiments (1-100 $\mu \mathrm{g}$ vs. $0.135-135 \mu \mathrm{g}$ ).

Serotonin exerts different actions on vascular smooth muscles which may result in either contraction or relaxation of the affected vessels. The type of response depends on the vessels studied (Saxena et al. 1978; Blackshear et al. 1985), the animal species, and the experimental or pathological conditions (Vanhoutte 1982; Heistad et al. 1988). In skeletal muscle (Fox et al. 1961; Merril et al. 1974) 5-HT has been shown to be an almost pure vasodilator, but there is only little evidence for vascular effects of 5-HT in joint tissue. In mongrel dogs (Dick et al. 1976) an enhanced blood flow in synovial microcirculation to 5-HT was observed, monitored indirectly by the clearance of radioactive xenon. For estimating the relative potency of 5-HT in exciting and sensitizing fine afferents from cat knee joint it is quite important to know whether 5-HT has a vasodilative or vasoconstrictive effect in joint tissue, especially in arthritis. Any reduction of blood flow in the knee joint capsule interferes with or reduces the delivery of substances injected i.a. The vasoconstriction to 5-HT applied i.a. visualized in cat arthritic knee joints by the reduction of $\mathrm{KCl}$ evoked responses, the diminished access of Evans blue injected i.a. to the joint capsule and the uncoupling of the responses of pacinian corpuscles even to $1.35 \mu \mathrm{g}$ of 5 -HT make it likely that, in inflamed joints, the smallest dose of 5 -HT tested $(0.135 \mu \mathrm{g})$ already impedes access of subsequent larger doses and therefore modifies the discharges of afferent group III and group IV units. The rather long latencies of 5-HT evoked responses in 4 units from inflamed joints might be the consequence of such pronounced vasoconstriction and a longer transit time.

The reduced responses to 5-HT on repeated applications may mainly be due to residual vasoconstriction from prior doses. However, receptor tachyphylaxis appears to be more important since the strongest vasoconstrictor responses occurred in inflamed joints where only weak tachyphylaxis occurred. In addition, tachyphylaxis is not restricted to close arterial-injected 5-HT but is also seen with potent vasodilators as BK (Kanaka et al. 1976), histamine (Herbert and Schmidt 1986), and prostaglandins (Schaible and Schmidt 1988).

At first view the vasoconstriction or transient vasospasm to 5-HT in arthritis seems surprising since blood flow is usually increased in inflamed tissues. Similar to other pathological conditions, i.e., atherosclerosis (Heistad et al. 1988a), it has to be taken into account that in inflamed joints the responsitivity of the vasculature or particularly of the endothelium to exogenously applied 5-HT might be enhanced or quite different from that in normal joints.

\section{References}

Armstrong, D., Dry, R.M.L., Keele, C.A. and Markham, J.W., Observation on chemical excitants of cutaneous pain in man, J. Physiol. (Lond.), 120 (1953) 326-351.

Artigas F., Sarrias, M.J., Martinez, E. and Gelpi, E., Serotonin in body fluids: characterization of human plasmatic and cerebrospinal fluid pools by means of a new HPLC method, Life Sci., 37 (1985) 441-447.

Beck, P.W. and Handwerker, H.O., Bradykinin and serotonin effects on various types of cutaneous nerve fibers, Pflügers Arch., 347 (1974) 209-222.

Birrell, G.J., McQueen, D.S., Iggo, A. and Grubb, B.D., The effects of 5-HT on articular sensory receptors in normal and arthritic rats, Br. J. Pharmacol., 101 (1990) 715-721.

Blackshear, J.L., Orlandi, C., Garnic, J.D. and Hollenberg, N.K., Differential large and small vessel responses to serotonin in the dog hindlimb in vivo: role of the $5 \cdot \mathrm{HT}_{2}$ receptor, J. Cardiovasc. Pharmacol., 7 (1985) 42-49.

Capasso, F., Dunn, C.J., Yamamoto, S., Willoughby, D.A. and Giroud, J.P., Further studies on carrageenan-induced pleurisy in rats, J. Pathol., 116 (1975) 117-124.

Colpaert, F.C., Evidence that adjuvant arthritis in the rat is associated with chronic pain, Pain, 28 (1987) 201-222.

Costa, E. and Rinaldi, F., Biochemical and electroencephalographic changes in the brain of rabbits injected with 5-hydroxytryptophan (influence of chlorpromazine premedication), Am. J. Physiol., 194 (1958) 214-220. 
Crunkhorn, P. and Meacock, S.C.R., Mediators of the inflammation induced in the rat paw by carrageenin, Br. J. Pharmacol., 42 (1971) 392-402.

Dick, W.C.. Grennan, D.M. and Zeitlin, 1.J., Studies on the relative effects of prostaglandins, bradykinin, 5-hydroxytryptamine and histamine on the synovial microcirculation in dogs, Br. J. Pharmacol., 56 (1976) 313-316.

Di Rosa, M., Giroud, J.P. and Willoughby, D.A., Studies of the mediators of the acute inflammatory response induced in rats in different sites by carrageenan and turpentine. J. Pathol., 104 (1971) 15-29.

Erspamer, V., Über den 5-Hydroxytryptamingehait des MagenDarmtraktes bei den Wirbeltieren, Naturwissenschaften, 40 (1953) $318-319$.

Erspamer, V., Occurence of indolealkylamines in nature. In: $O$. Eichler and A. Farah (Eds.), Handbook of Experimental Pharmacology, Vol. 19. Springer. Heidelberg, 1966, pp. 133-181.

Fekete, M. and Kürti, A.M., Effect of monoamine oxidase inhibitors on rat paw edema induced by various phlogistic agents, Eur. J. Pharmacol., 10 (1970) 268-276.

Feldman, S., Izak, G. and Nelken, D., Blood coagulation studies and serotonin determination in serum and cerebrospinal fluid in multiple sclerosis, Acta Psychiat. Scand., 32 (1957) 37-49.

Fock, S. and Mense, S., Exitatory effects of 5-hydroxytryptamine, histamine and potassium on muscular group IV afferent units: a comparison with bradykinin, Brain Res., 105 (1976) 459-469.

Fox. R.H., Goldsmith, R., Kidd, D.J. and Lewis, G.P., Bradykinin as a vasodilator in man, J. Physiol. (Lond.), 157 (1961) 589-602.

Franz, M. and Mense, S., Muscle receptors with group IV afferent fibers responding to application of bradykinin, Brain Res., 92 (1975) 369-383

Garattini, S. and Valzelli, L., Serotonin, Elsevier, Amsterdam. 1965

Garcia Leme, J., Hamamura, L., Leite, M.P. and Rocha de Silva, M. Pharmacological analysis of the acute inflammatory process induced in the rat's paw by local injection of carrageenin and by heating. Br. J. Pharmacol., 43 (1973) 88-96.

Guzman. F., Braun, Ch. and Lim, R.K.S., Visceral pain and the pseudaffective response to intra-arterial injection of bradykinin and other algesic agents, Arch. Int. Pharmacodyn., 136 (1962) 353-384.

Hardeman, M.R., Den Uyl. A. and Prins, H.K., A semi-mechanized method for the fluorometric determination of 5-hydroxytryptamine (serotonin) in blood plasma and platelets, Clin. Chim. Acta, 37 (1972) 71-79.

He, X., Schmidt, R.F. and Schmittner, H., Effects of capsaicin on articular afferents of the cat's knee joint, Agents Actions, 25 (1988) 222-224

He. X., Schepelmann, K., Schaible, H.-G. and Schmidt, R.F., Capsaicin inhibits responses of fine afferents from the knee joint of the cat to mechanical and chemical stimuli, Brain Res., 530 (1990) $147-150$

Heistad, D.D., Armstrong, M.L., Brown, B. and Harrison, D.G. Responsiveness to serotonin in atherosclerotic blood vessels. In: P.M. Vanhoutte, Vasodilatation: Vasuclar Smooth Muscle, Peptides, Autonomic Nerves, and Endothelium, Raven Press, New York, 1988, pp. 249-254.

Heppelmann, B., Schaible, H.-G. and Schmidt, R.F., Effects of prostaglandins $E_{1}$ and $E_{2}$ on the mechanosensitivity of group III afferents from normal and inflamed cat knee joints. In: H.L. Fields et al. (Eds.), Advances in Pain Research and Therapy, Vol. 9. Raven Press, New York, 1985, pp. 91-101.
Heppelmann, B., Pfeffer, A., Schaible, H.-G. and Schmidt, R.F. Effects of acetylsalicylic acid and indomethacin on single goups III and IV sensory units from acutely inflamed joints, Pain, 26 (1986) 337-351.

Herbert, M.K. and Schmidt, R.F., Activation of Group III and IV afferent units from normal and inflamed cat knee joints by histamine, Neurosci. Lett., Suppl. 26 (1986) S521.

Herbert, M.K., Schmidt. R.F. and Weis, K.H., Effect of substance P on fine afferents from cat's knee joints, Eur. J. Anaesthesiol.. 6 (1989) 74.

Kanaka, R., Schaible, H.-G, and Schmidt, R.F., Activation of fine articular afferent units by bradykinin, Brain Res., 327 (1985) 81-90.

Keele, C.A. and Armstrong. D., Substances producing pain and itch, Edward Arnold, London, 1964.

Lim, R.K.S., Liu, Ch.N., Guzman, F. and Braun, Ch., Visceral receptors concerned in visceral pain and the pseud-affective response to intra-arterial injection of bradykinin and other algesic agents, J. Comp. Neurol., 118 (1962) 269-293.

Lindahl, O., Experimental skin pain induced by injection of watersoluble substances in humans, Acta Physiol. Scand., 51. Suppl. 179 (1961) 1-90.

Mense, S. and Schmidt, R.F.. Activation of group IV afferent units from muscle by algesic agents, Brain Res., 72 (1974) 305-310.

Merril, G.F., Kline, R.L., Haddy, F.J. and Grega, G.J., Effects of locally infused serotonin on canine forelimb weight and segmental vascular resistance, J. Pharmacol. Exp. Ther., 189 (1974) $140-148$.

Robertson, J.I.S., Peart. W.S. and Andrews, T.M., The mechanism of facial flush in the carcinoid syndrome, Quart. J. Med., 31 (1962) $103-123$.

Russel, N.J.W., Schaible, H.-G. and Schmidt, R.F.. Opiates inhibit the discharges of fine afferent units from inflamed knee joint of the cat, Neurosci. Letl.. 76 (1987) 107-112.

Saxena, P.R. Forsyth, R.P., Johnston, B. and de Werk. A., Regional and systemic haemodynamic changes evoked by 5-hydroxytryptamin in awake and anaesthetized rabbits, Eur. J. Pharmacol., 50 (1978) $61-68$.

Schaible, H.-G. and Schmidt, R.F., Responses of fine medial articular nerve afferents to passive movements of knee joint, J. Neurophysiol., 49 (1983) 1118-1126.

Schaible, H.-G. and Schmidt, R.F., Effects of an experimental arthritis on the sensory properties of fine articular afferent units, J. Neurophysiol., 54 (1985) 1109-1122.

Schaible, H.-G. and Schmidt, R.F., Excitation and sensitization of fine articular afferent units from cat's knee joint by prostaglandin $E_{2}$ (PG E $E_{2}$ ), J. Physiol. (Lond.), 403 (1988a) 91-104.

Schaible, H.-G. and Schmidt, R.F.. Time course of mechanosensitivity changes in articular afferents during a developing experimental arthritis, J. Neurophysiol., 60 (1988b) 2180-2195.

Schepelmann, K., Messlinger, K., Schaible, H.-G. and Schmidt, R.F., Prostaglandin $I_{2}$ enhances the mechanosensitivity of fine afferents from the knee joint of the cat, Pflüger's Arch., 415 (1990) R107.

Spector, W.G. and Willoughby, D.A., The inflammatory response, Bact. Rev., 27 (1964) 117-154.

Vanhoutte, P.M., Does 5-hydroxytryptamine play a role in hypertension?, Trends Pharmacol. Sci., 3 (1982) 370-373.

Zeitlin, I.J, and Smith, A.N., 5-Hydroxyindoles and kinins in the carcinoid and dumping syndromes. Lancet, ii (1966) 986-991. 